\title{
Abandoning the EPP-feature in Polish dual copula clauses by redefining the predication relation
}

\author{
Rafał Jurczyk \\ WSB University in Opole, Poland
}

\begin{abstract}
This paper questions the logic behind the presence and the working of the EPP-feature in Polish dual copula clauses (henceforth, DCCs) with the pronominal copula to, the verbal copula być 'to be', and two nominative $3^{\text {rd }}$ person DPs, as represented in Bondaruk (2019). The criticism follows from: (i) - Chomsky's (2000, 2001) downward Agree operation; (ii) - the view that the predicator encodes the predication relation between the pre-copular subject and the post-copular predicate; (iii) - selective multiple Agree, whereby the satisfaction of the EPP- and u $\varphi$-features is divorced. Adopting (i)-(iii), Bondaruk's scrutiny allows either the pre- or the post-copular DP to occupy SpecTP, thereby accounting for DCCs' agreement and configurational patterns, but, simultaneously, suffering from theoretical shortcomings it creates. We argue for a simpler satisfaction of the subject requirement which does not rely on the troublesome EPP-feature, but is motivated formally by the relation between $\mathrm{T}$ and the higher DP. We derive this requirement by following Zeiljstra's (2012) upward Agree which only takes place once interpretable features c-command uninterpretable features, and Rothstein's (2004) approach which is based on a neoDavidsonian event semantics and which argues that $b e$ and its complement form a complex predicate, separated from the pre-copular DP both semantically and syntactically.
\end{abstract}

Keywords: EPP, predication, proposition, dual copula clauses (DCCs), Agree

\section{Introduction ${ }^{12}$}

Originating in early 1980's (Chomsky 1981, 1982), the Extended Projection Principle (henceforth, EPP) requires each clause to have a subject (Svenonius 2002: 9). ${ }^{3}$ Initially

1 This paper focusses only on bi-nominative to być copular sentences with the obligatory pronominal copula to that invariably requires $\mathrm{DP}_{2}$ in the nominative, and the verbal copula być 'to be' that can be dropped in the present tense. See section 2.2.2 for discussion.

2 Abbreviations used in the paper: DCC - a dual copula clause, NOM - nominative, GEN - genitive, DAT dative, INSTR - instrumental, SG - singular, PL - plural, MASC - masculine, FEM - feminine, NEUT - neuter, N-VIR - non-virile, COP - nominal copula to, IMPERF - imperfective, 1 - first person, 2 - second person, 3 third person, $\mathrm{u}$ - unvalued, $\mathrm{i}$ - interpretable

3 There are various approaches to the EPP. For Rizzi (1982), EPP is exclusively subject-oriented, necessitating either lexical or null subjects, depending on the richness of verbal agreement (cf. Biberauer and Roberts 2010; 
considered from various standpoints (morphophonological - Holmberg 2000; semantic Rothstein 1983; Williams 1980), it is now usually conflated with syntactic attributes (but see Kiss 2002; Roberts and Roussou 2002). Early Minimalism (Chomsky 1995) formalised the EPP as an independent $\mathrm{D}$-feature on $\mathrm{T}$ and DPs, the one on $\mathrm{T}$ [-interpretable; +strong] and requiring checking. This checking, although involving lexical items, motivated SpecTP and movement therein structurally (Chomsky 1995: 341), for besides lexical subjects, SpecTP can also host semantically empty expletives. Later Minimalism (e.g. Chomsky 2001) strengthened the EPP's syntactic status, making it an uninterpretable selectional feature (Chomsky 2001: 9) and the EPP-requirement purely configurational. Al-Horais (2013) and Lasnik (2001) observe, for instance, that DP-movement to SpecTP does not value T's EPP-feature because DP lacks this feature. ${ }^{4}$ Contrastively, other formal features on $\mathrm{T}$ and $\mathrm{DP}$ (e.g. $\varphi$-features) require no movement, being valued at a distance by Chomsky's $(2000,2001)$ Agree relation. ${ }^{5}$

Such a configurational guise of the EPP-feature is found in Polish DCCs. An example of a DCC is (1), featuring two nominative $3^{\text {rd }}$ person DPs and two copulas (pronominal to and verbal $b y c$ ' to be'), the latter agreeing in $\varphi$-features with the post-verbal DP. ${ }^{6} 7$

Holmberg 2010). Alboiou (2000) parameterises the EPP-feature itself, manifestable as D-feature (requiring DP in SpecTP), V-feature (requiring V-movement to T), or T-feature (requiring a predicate XP in SpecTP). For Sigurðsson (2003), the nominative is checked already within $v \mathrm{P}$ and DP-movement to SpecTP is due to Person Prominence Principle, i.e., the requirement that the person feature be visualised at the leftmost edge of TP (Sigurðsson's IP/PersP). To substantiate this claim, he considers the so-called quirky subject constructions (i)(ii), whereby the verb shows $3^{\text {rd }}$ person 'defective agreement' with the initial dative argument, and only number agreement with the post-verbal nominative argument (in this respect, cf. also section 2.2.3 and the feature mismatch in DCCs with initial $3^{\text {rd }}$ person DPs, as opposed to DCCs with initial $1^{\text {st }}$ and $2^{\text {nd }}$ person DPs).

(i) ${ }^{\star}$ Mér höfðudleiðst pið

me-DAT had-2-PL bored you-NOM

'I had found you boring'

(ii) Mér höfðu leiðst peir

me-DAT had-3-PL bored they-NOM

'I had found them boring.'

For Haeberli (2003), DP-movement to SpecTP is a formal requirement because T's [T+, V+, D-, N-] and D's $[\mathrm{D}+, \mathrm{N}+, \mathrm{T}-, \mathrm{V}-]$ feature matrices must become valued/positive by the end of the derivation. The movement of a D-category thus follows from T's negatively specified categorial feature [D-]. This approach resembles the one advanced here which takes the DP-movement to SpecTP to be due to T's lack of the inherent nominal property (cf. section 2.2.1) (we thank Reviewer 2 for bringing this similarity to our attention).

4 We disregard here the Edge Feature, EPP's incarnation in the 'phase theory era' (e.g. Chomsky 2001). It attracts lexical items to the phasal edge so they can participate in further syntactic operations.

5 Following Chomsky (2000: 101, 121-123) and Chomsky (2001: 3-6), the Agree relation can be taken to hold between $\alpha$ (Probe) and $\beta$ (Goal) if: (i) - $\alpha$ carries unvalued $\varphi$-features; (ii) - $\beta$ carries valued $\varphi$-features and an unvalued case feature; (iii) - $\alpha$ c-commands $\beta$; (iv) $-\alpha$ and $\beta$ are active i.e., possess unvalued features; (v) - there is no $\gamma$ closer to $\alpha$ than $\beta$, even if $\gamma$ is inactive (cannot agree with $\alpha$ ).

6 Despite numerous analyses, the status of the Polish particle to remains unresolved. See section 2.2.2 for a more detailed discussion.

7 Bondaruk (2019) and Citko (2008) offer most comprehensive accounts on Polish DCCs, though the former is more detailed and handles phenomena (e.g. agreement with $\mathrm{DP}_{2}$ ) the latter cannot (see Bondaruk 2013 for details). Given that, and the fact that problematic issues we address are largely shared (although with some 


(1) to okolica ${ }^{\star}$ była $\quad$ / byty
this neighbourhood-NOM-3-SG-FEM COP ${ }^{*}$ was-3-SG-FEM / were-3-PL-N-VIR
obrzeżar miasta
outskirts-NOM-3-PL-NEUT of-city
'This neighbourhood was the outskirts of the city'

This $\varphi$-agreement pattern compels Bondaruk (2019) to dissociate the satisfaction of the EPPfeature from the valuation of T's $\varphi$-features (contra Chomsky 2008, 2001). T probes the preand the post-copular DP (henceforth, $\mathrm{DP}_{1}$ and $\mathrm{DP}_{2}$, respectively) for different features (contra Hiraiwa 2005, where a single Probe and multiple Goals share their features), an instance of selective multiple Agree which she adopts to account for two DCC types. These are predicational (1) and specificational (2) DCCs, their simplified derivations shown in (3)-(4), respectively (numeral indexes show feature valuation scenarios).
(2) Obrzeża miasta to była / *byly
outskirts-NOM-3-PL-NEUT of-city COP was-3-SG-FEM / *were-3-PL-N-VIR
ta okolica
this neighbourhood-NOM-3-SG-FEM
'The outskirts of the city were this neighbourhood'

(3) $\quad\left[{ }_{\text {TP }} \mathrm{DP}_{[1]}\left[\mathrm{T}_{[\mathrm{EPP} 1 \text {; up } 2]}\right.\right.$ to $\left.\left.\left[\mathrm{vPP}_{[2]} \mathrm{V}_{\mathrm{DP}[1]} \mathrm{DP}_{[2]}\right]\right]\right]$

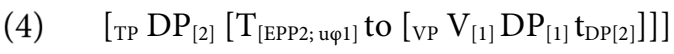

T probes both DPs simultaneously and being finite ( $\varphi$-complete) it values their case-features as nominative (Bondaruk 2019: 127) ${ }^{8}$ In return, selective multiple Agree allows each DP to satisfy one of T's features (EPP or $\varphi$ ). This picture is, however, problematic.

First, multiple valuation of $\mathrm{u}$-case features as nominative by $\mathrm{T}$ is dubious. In (4), for instance, $\mathrm{T}$ probes $\mathrm{DP}_{1}$ for $\varphi$-features (valuing in return its $\mathrm{u}$-case feature) and $\mathrm{DP}_{2}$ for EPP reasons. Given that, the valuation of $\mathrm{DP}_{2}$ 's u-case feature becomes murky, for T's $\mathrm{u} \varphi$-features have already been valued by $\mathrm{DP}_{1}$. No property inherent in $\mathrm{T}$ seems to motivate multiple Agree, even if T probes both DPs simultaneously, escaping the Defective Intervention Constraint (henceforth, DIC) effects. ${ }^{9}$ Whilst T's u $\varphi$-features necessitate agreement with an appropriate Goal, this in no way implies multiple Agree. A single Goal $\left(\mathrm{DP}_{1}\right)$ suffices to value T's features, which completes the Agree relation between the two, manifested by the verb's $\varphi$-agreement with $\mathrm{DP}_{1}$ only.

Second, the movement of the farther $\mathrm{DP}_{2}$ in specificational DCCs violates relativised minimality effects (Rizzi 1990; Zeiljstra 2012), whereby a syntactic operation between A and C is blocked if another constituent $\mathrm{B}$, capable of satisfying it, intervenes between the two. To circumvent the problem of $\mathrm{DP}_{2}$ movement to SpecTP, Bondaruk (2019) follows Mikkelsen's

alterations, highlighted whenever necessary) by both approaches, we focus here on the critical analysis of Bondaruk's approach.

8 This operation is Chomsky's (2001) approach to case checking as a reflex of valuing T's u $\varphi$-features, for T's formal content is $\left[\mathrm{u} \varphi\right.$; EPP] and $\mathrm{DP}_{1}$ and $\mathrm{DP}_{2}$ are $[\mathrm{i} \varphi$; $\mathrm{u}$-case].

9 According to DIC, Agree cannot involve Probe $\alpha(\mathrm{T})$ and Goal $\gamma\left(\mathrm{DP}_{2}\right)$ in $\alpha>\beta>\gamma, \beta\left(\mathrm{DP}_{1}\right)$ being inactive, having already agreed with a (Chomsky 2000: 123). 
(2005) idea and adopts a topic-feature-based dependency holding exclusively between $\mathrm{T}$ and $\mathrm{DP}_{2}$, the feature which $\mathrm{DP}_{1}$ lacks and, consequently, does not intervene between them. The postulation of this topic-feature is due to the fact that $\mathrm{DP}_{2}$ in specificational DCCs represents discourse-old information (Bondaruk 2013: 278-279, 2019: 123-124; Mikkelsen 2005: 163). Nevertheless, the very necessity of circumventing both the DIC effects (by means of multiple Agree) and the relativised minimality effects (by means of additional features) in itself suggests that Agree and movement phenomena should both be confined to locality conditions.

Third, as Haider (2016: 25) observes with respect to the EPP: "[i]t does not refer to a property of linguistic signs but to the result of a derivation". The EPP is thus not a feature, for it presupposes no valuation between the Probe and the Goal. But then, what drives SpecTP movement of DPs in DCCs if the EPP-satisfaction lacks formal motivation? Furthermore, since in Bondaruk (2019: 120) the EPP-requirement simply states that SpecTP be occupied i.e., it allows for SpecTP-movement of DP which does not necessarily value T's $u \varphi$-features, what (and why) determines whether the EPP is satisfied by $\mathrm{DP}_{1}$ or by $\mathrm{DP}_{2}$ ? If, as Bondaruk (2019: 123) herself notes, SpecTP-movement may also be determined by the topic feature (the proposal in itself devised just to bypass the relativised minimality effects) of $\mathrm{DP}_{2}$ in specificational DCCs, then the claim that the EPP requirement only requires a lexically occupied SpecTP is simply false. Essentially, the proposal that different DPs may satisfy the EPP requirement merely restates the observation in formal terms, but does not explain why DP-movement patterns in DCCs are the way they are.

These issues will receive a principled explanation once the subject requirement operates exclusively within the reformulated Chomsky's (2001) Agree relation (holding only if i-features c-command $\mathrm{u}$-features) coupled with the reformulated predication relation (holding between $\mathrm{DP}_{1}$ and $b y c ́$ + $\mathrm{DP}_{2}$ complement).

The paper is organised as follows. Section 2.1 briefly reviews Polish DCCs. Section 2.2 covers the analysis. Section 2.2.1 highlights the problematic status of the EPP in Chomsky's $(2000,2001)$ Agree operation. Next, it offers an alternative take on the EPP which is based on Zeiljstra's (2012) upward Agree and motivated by formal-semantic relations involving the finite $\mathrm{T}, \mathrm{DP}_{1}$, and $v \mathrm{P} / \mathrm{VP}$ in contexts with lexical verbs. The subject requirement thus obtained is invariably satisfied by $\mathrm{DP}_{1}$ separated syntactically and semantically from the predicate and asserted its semantic property. Section 2.2.2 extends the subject requirement as defined in section 2.2.1, to hold also of DCCs. It does so by additionally drawing from Rothstein's (2004) approach to predication built on a neo-Davidsonian event semantics. Some space is also devoted to determining the status and the role of the nominal copula to. Section 2.2.3 briefly outlines the derivation of Polish DCCs within the confines of the approach advanced in sections 2.2.1 and 2.2.2. Section 3 concludes the discussion. 


\section{Eliminating the EPP-feature from Polish dual copula clauses}

\subsection{General remarks on dual copula clauses $^{10}$}

Polish DCCs are clauses with the pronominal copula to and the verbal copula być 'to be', surrounded by two nominative DPs. The different configuration of these DPs with respect to być produces two types of DCCs, predicational (1) and specificational (2). ${ }^{11}$ In (1), the initial DP ta okolica 'this neighbourhood' is ascribed the property of being the outskirts of the city by $\mathrm{DP}_{2}$ predicate obrzeża miasta 'outskirts of the city'. In (2), the order is reversed, with the initial $\mathrm{DP}_{2}$ predicate obrzeża miasta specified by $\mathrm{DP}_{1}$ ta okolica. The agreement in DCCs is always the same; the verbal copula agrees with a post-copular DP. This pattern is characteristic of DCCs only, for dropping to yields $\varphi$-agreement between $\mathrm{DP}_{1}$ and the copula (5)-(6). ${ }^{12}{ }^{13}$

10 This section only highlights key aspects for our scrutiny. For a comprehensive, multi-faceted survey of copular clauses in Polish (and English), see Bondaruk (2013).

11 For Błaszczak and Geist (2000: 118, 124, 2001: 247, 251) (but see also Geist 2007 for similar remarks on Russian), Polish predicational copular clauses lack to, featuring only the verbal copula być 'to be' and the instrumental case-marked DP (e.g. Piotr jest moim nauczycielem, lit. 'Peter is my INSTR teacher ${ }_{\text {INSTR }}$ '). Błaszczak and Geist argue that to behaves similarly to coordinating conjunctions, namely, it functions as a linking device establishing the relation between two constituents. Consequently, they classify DCCs not as predicational, but specificational or equative (Błaszczak and Geist 2000: 124). For details on what determines the specificational and equative interpretation, see Geist (2007).

12 Unlike English, Polish does not use articles so its bare $\mathrm{DPs}_{2}$ in (5)-(6) are predicate-denoting despite being translated by definite DPs. See Geist (2007) for similar considerations on Russian, another article-less language, and English. Consult Bondaruk (2019) and, especially, Bondaruk (2013) for an overview of tests/analyses to distinguish predicational from specificational copular clauses.

13 The interpretation of clause (5) somewhat differs from that of clause (6). For example, while to być $+\mathrm{DP}_{\mathrm{NOM}}$

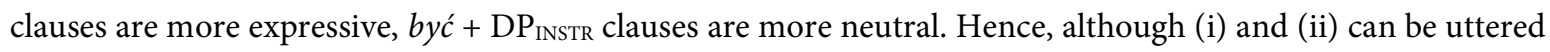
to emphasize that 'this neighbourhood' is part of the city, (ii) is more suggestive, implying anger or frustration.

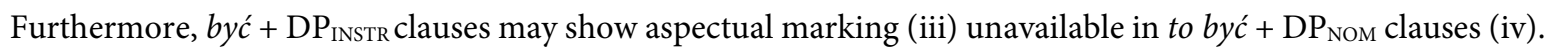
See Bondaruk (2014, 2013: 152-155, 214-216) for more detailed remarks on the interpretational differences between different types of Polish copular clauses.

(i) Ta okolica byłaobrzeżami miasta, a nie jakąśtam wioska this neighbourhood-NOM was outskirts-INSTR of-city, and not some-INSTR any village-INSTR 'This neighbourhood was the outskirts of the city, and not just any village'

(ii) Ta okolica to byty obrzeża miasta, a nie jakaśtam wioska this neighbourhood-NOM COP were outskirts-NOM of-city, and not some-NOM any village-NOM 'This neighbourhood was the outskirts of the city, and not just any village'

(iii) Ta okolica bywała obrzeżami miasta, ale to dawne czasy this neighbourhood-NOM was-IMPERF outskirts-INSTR of-city, but it old-NOM times-NOM 'This neighbourhood was the outskirts of the city, but that was a long time ago.'

(iv) ${ }^{\star}$ Taokolica to bywaly obrzeża miasta,ale todawne czasy this neighbourhood-NOM COP was-IMPERF outskirts-NOM of-city, but it old-NOM times-NOM 'This neighbourhood was the outskirts of the city, but that was a long time ago.' 
(5) Ta okolica była / *byty

This neighbourhood-NOM-3-SG-FEM was-3-SG-FEM / ${ }^{*}$ were-3-PL-N-VIR

obrzeżami miasta

outskirts-INSTR-3-PL-NEUT of-city

'This neighbourhood was the outskirts of the city'

(6) Ta okolica to *była I byty

This neighbourhood-NOM-3-SG-FEM COP * was-3-SG-FEM / were-3-PL-N-VIR

obrzeża miasta

outskirts-NOM-3-PL-NEUT of-city

'This neighbourhood was the outskirts of the city'

Citko (2008) offers some remarks on the syntax and semantics of DCCs (e.g. their typological status or extraction/movement phenomena), but provides little as regards their agreement patterns. In fact, she only discusses contexts where T and two DPs agree in $\varphi$-features (7). ${ }^{14}$

$\begin{array}{lll}\text { Warszawa to jest } & \text { stolica } & \text { Polski } \\ \text { Warsaw-NOM-3-SG COP } & \text { is-3-SG capital-NOM-3-SG of Poland-GEN-3-SG } \\ \text { 'Warsaw is the capital of Poland' }\end{array}$

For her, $\mathrm{T}$ has a complete set of $\mathrm{u} \varphi$-features and undergoes multiple Agree with both DPs, valuing their $\mathrm{u}$-case features as nominative (cf. Hiraiwa 2002). T, in return, has its $\mathrm{u} \varphi$-features valued as $3^{\text {rd }}$ person-SG. T also carries the EPP-feature which triggers the movement of the closer DP to SpecTP. In contrast to Bondaruk (2019), Citko's multiple Agree is thus nonselective, for T probes both DPs for the same features. This obviously blurs the picture of verbal agreement whenever two DPs show $\varphi$-features mismatch, although Citko does not address this issue. Bondaruk's (2019) perspective partly overlaps with Citko (2008) (e.g. the finite T also values the u-case features of two DPs as nominative), but given the problem that Citko's (2008) approach faces, Bondaruk formulates a more advantageous proposal. Based on selective multiple Agree, it allows to account for the valuation of T's $\mathrm{u} \varphi$-features and the EPP-feature by two different DPs ((3)-(4)). These different feature valuation scenarios allow her to account for $\varphi$-agreement patterns between DPs and być, even if DPs show $\varphi$-features mismatch.

As for the structure of DCCs, they are frequently taken to feature syntactically manifested predication (but cf. Rutkowski 2006, who places to in T and base-generates the subject DP in Topic Phrase in the left periphery of the clause). Hence, despite certain differences, Bondaruk (2019) and Citko (2008) come up with partly overlapping cartographies (8)-(9). For convenience's sake, Citko's example (8) is imposed on Bondaruk's syntactic template in (9).

\footnotetext{
${ }^{14}$ DCCs like (6) or (7) may, of course, be turned into być $+\mathrm{DP}_{\text {INSTR }}$ clauses by dropping to and having the postcopular DP in instrumental.
} 
(8)

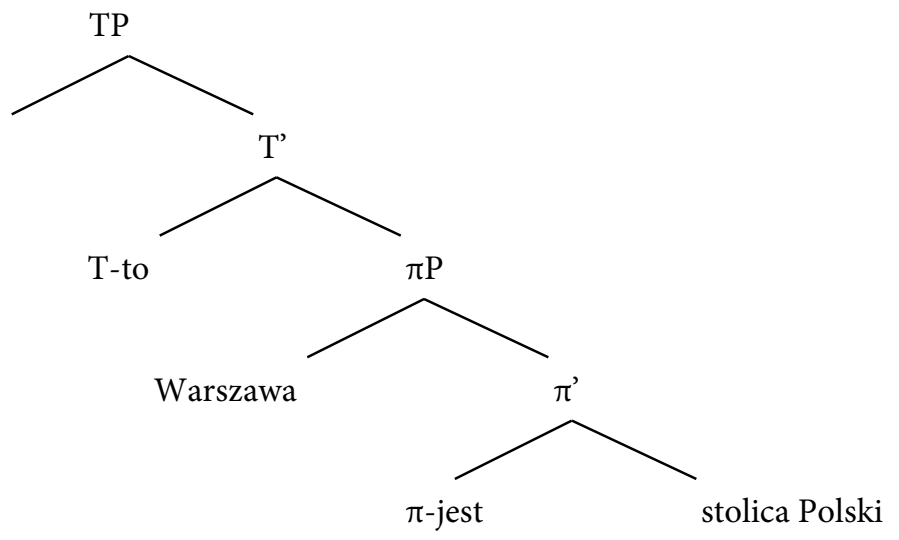

(9)

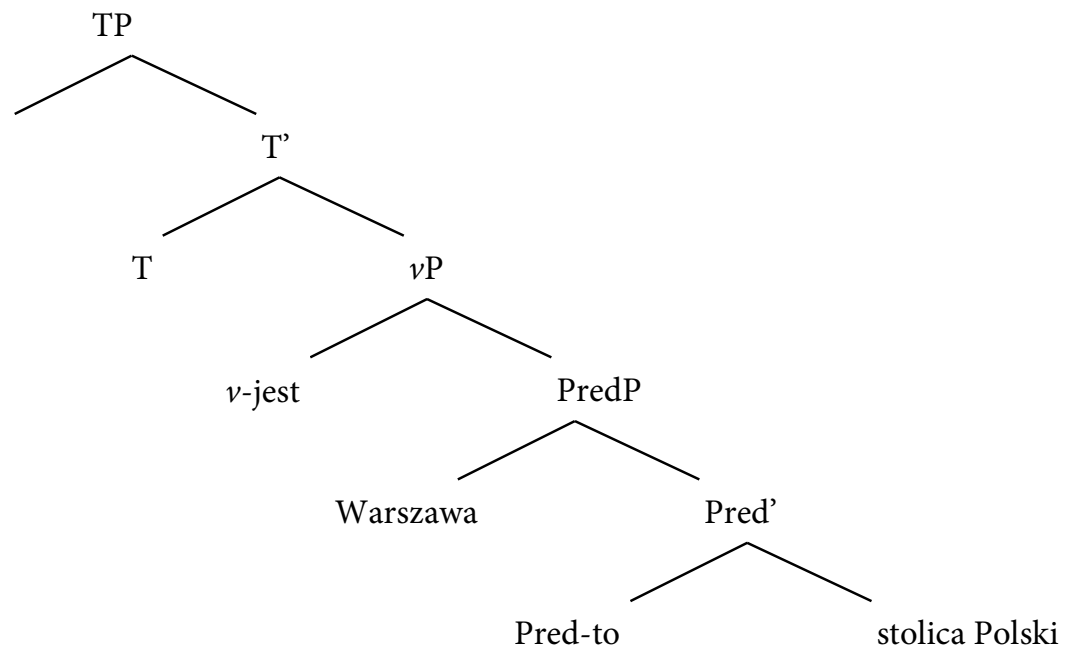

Citko's (2008) $\pi$ P-projection corresponds to Bondaruk's PredP, both authors following Bowers's (1993) idea that predication requires syntactic manifestation of the form [Predp subject [Pred Pred predicate]]. ${ }^{15}$ Its structure is ternary, centred around the predicator which expresses the relation between the subject (in SpecPredP) and the predicate (Pred's complement) of which neither is more prominent than the other. Citko correlates to and być with T and Pred, the latter LF-raising to $\mathrm{T}$ to provide to with the temporal property (since tense marking is manifested on the verb and not to). She takes the $\pi$ Pred head (the verbal copula) to be a coordination conjunction linking the same lexical categories (cf. also discussion in section 2.2.2). Bondaruk finds the temporal specification of to unappealing and relocates it to Pred, whilst defining być as a type of an unaccusative verb occupying v. Citko (2008) and Bondaruk (2019) both distinguish between defective and non-defective Pred. A non-defective Pred has $u \varphi$-features and is capable of valuing the instrumental case on DPs. A non-defective Pred can be found in

${ }^{15}$ An alternative approach to predication is offered by den Dikken (2006). For him, the predication relation between the subject and the predicate is encoded by the Relator Phrase (RP) with an abstract Relator head as shown in (i) (representation based on den Dikken 2006: 2-3, 11-13). In predicate inversion contexts, he takes the raised predicate to be connected, via the Linker, to a small clause containing the subject (ii) (representation based on den Dikken 2006: 113, 115). Though mediating the predication relation, Relators and Linkers are semantically empty functional heads. See den Dikken (2006) for motivations behind representations (i)-(ii).

(i) ${ }_{\mathrm{RP}}\left[\mathrm{XP}\right.$ SUBJECT [ ${ }^{\prime}$ RELATOR [Yे PREDICATE] $\left.\left.]\right]\right]$

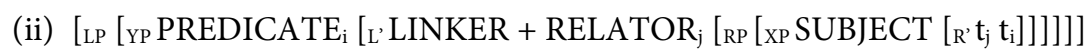


sentences with just a verbal copula as (5). A defective Pred lacks $u \varphi$-features and is unable to value DP's case. An example of a defective Pred can be found in DCCs as (1)-(2). That being said, the only probe in DCCs is the finite $\mathrm{T}$ whose $\mathrm{u} \varphi$-features and the [+multiple] property allow it to value the u-case features of two DPs as nominative.

\subsection{Reconsidering formal and semantic relations in DCCs}

\subsubsection{The EPP-requirement in general: Problems and solutions}

The downward Agree relation involves a Probe $(\alpha)$ with $u \varphi$-features and a Goal $(\beta)$ with i $\varphi$ features and a u-case feature. In Chomsky (2000, 2001), Agree is initiated by a Probe, a functional category (e.g. T), following linearly rightwards (downwards on a derivational tree) in accordance with the c-command condition. It is represented schematically in (10)-(11), example (11) translating to 'Tomek listens to Metallica'.

(10) $\left[\ldots \alpha_{[u \varphi p]} \ldots\right.$ PROBING $\left.\ldots \beta_{[i \varphi]} \ldots\right]$

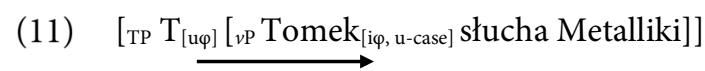

In (11), T carries u $\varphi$-features and probes down for the Goal (Tomek) with matching valued i $\varphi$ features. The Goal's valued $\varphi$-features assign the value to T's and, as a reflex of this agreement, Tomek has its u-case feature valued as nominative. This step completes the Probe-Goal Agree relation, which is why the subsequent movement of Tomek to SpecTP is triggered by T's EPPfeature. Intrinsically, the EPP's source is T's finite property i.e., $\varphi$-completeness (Chomsky 2001: 8-9) sanctioning T's Agree with the Goal in Spec $v$ P and making the latter an appropriate candidate to occupy SpecTP (Chomsky 2001: 4, 6). Notwithstanding, despite licensing nominative agreement and contributing to $v \mathrm{P}$ 's temporal reference, TP's role in Chomsky's works is marginalised. ${ }^{16}$ First, Agree between $\mathrm{T}$ and the subject does not contribute to semantics, T's $\mathrm{u} \varphi$-features being uninterpretable. Second, the fact that Agree is the (only) mechanism of feature valuation allows the subject, whose case feature have been valued at a distance, to receive Full Interpretation in Spec $v$ P. ${ }^{17}$ Hence, no further operation is necessitated by T's requirements in (12) (simplified, strikethrough represents feature valuation).

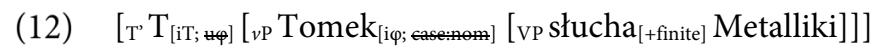

The role of the EPP-feature is thus twofold; causing the movement of the subject to SpecTP it also remedies the minor role that TP/T plays in the derivation. This remedy is, however, illusive and leads to circularity. As Haider (2016: 25) observes, the subject moves because of the EPP-

\footnotetext{
${ }^{16}$ In Chomsky $(2000,2001)$ the finite $\mathrm{T}$ no longer has the categorial $+\mathrm{V}$-feature (the formal $\mathrm{T}-\mathrm{V}$ dependency advocated earlier in Chomsky (1995) is abandoned). In Chomsky (2008), temporal properties of $\mathrm{T}$ are further reduced and $\mathrm{T}$ only receives its Tense and $\varphi$-features from $\mathrm{C}$, a phase head.

17 Full Interpretation dictates that all features receive interpretation by the time they reach the PF and LF interfaces (Chomsky 1995: 130).
} 
feature whose presence, in turn, follows from the presence of the subject. Here, we will adopt an alternative view on the subject-requirement as operating within the tenets of Zeiljstra's (2012: 17) upward Agree which complies with the requirement that under Agree i-features ccommand u-features. ${ }^{18}$

(13) Agree: $\alpha$ can Agree with $\beta$ iff:

a. $\alpha$ carries at least one uninterpretable feature and $\beta$ carries a matching interpretable feature.

b. $\beta$ c-commands $\alpha$.

c. $\beta$ is the closest goal to $\alpha$.

Given that the subject requirement is satisfied by the nominative DP i.e., DP with a specific [i $\varphi$, $\mathrm{uT}$ ] featural matrix, we propose that all instances of Agree (in $\varphi$ - and case-features) between $\mathrm{T}$ and this DP are constrained by (13a-b) (for now, we disregard (13c)). As regards the nominative case-feature, we assume (contra Bondaruk 2019) that it does not crop up as a reflex of DP's $\varphi$ agreement with T, but is simply the uT-feature (see Pesetsky and Torrego 2004). ${ }^{19}$ The way the subject requirement now operates is as follows. The nominative DP carries the uT-feature and by virtue of (13a) it functions as a Probe (Goal in Chomsky's Agree) that looks upwards for the interpretable counterpart which it finds on T. Since in this instance of Agree the i-feature ccommands the $\mathrm{u}$-feature, it satisfies (13b) and SpecTP-movement is unnecessary. The next instance of Agree involves T's $u \varphi$-features. By virtue of (13a), T is a Probe and looks downwards for the $i \varphi$-features which it locates on the nominative DP. Because in this case $\mathrm{i}$-features do not c-command u-features, Agree cannot take place and, hence, to satisfy (13b) SpecTP-movement of DP is necessary. The EPP-requirement thus becomes formal for the sake of checking T's $u \varphi$ features.

One could ask, however, why it is T's u $\varphi$-features that determine the subject requirement. Put differently, why does Agree operate the way as captured in (13)? We believe this is due to T's properties. T is often labelled as 'extensional' with respect to the thematic $v \mathrm{P}$-/VP-domain (e.g. Boeckx 2008: 152-155; Vangsnes 2002), providing the verb's event denotation with temporal interpretation and allowing $v \mathrm{P} / \mathrm{VP}$ to 'expand' and connect to the CP-domain expressing force and/or mood (cf. Roberts and Roussou 2002). Biberauer and Roberts (2010:

18 In (13), the driving force of Agree is the uninterpretable and not the unvalued status of the Probe's feature. In Chomsky $(2001,2000)$, valuation does not seem to be a sufficient trigger for Agree, for it is still possible for multiple DPs with inherently/lexically valued $\varphi$-features to participate in a single Agree relation (e.g. in Japanese multiple nominative constructions - see Hiraiwa 2005, Ura 2000). An alternative to Zeiljstra's approach is offered by Bošković (2002). He rejects the EPP arguing that SpecTP must be occupied due to the Inverse Case Filter (cf. Bošković 1997), namely, the requirement that traditional Case assigners assign case features (nominative for $\mathrm{T}$ ). This requires that case features be under c-command, for they are uninterpretable on both Case assigner and assignee. Hence, the overt movement of the latter to SpecTP (Bošković 2002: 172). Elsewhere, Alexiadou and Agnostopoulou $(2001,2007)$ offer a principled version of the EPP based on The Subject in-situ Generalisation which says that by Spell-out, $v \mathrm{P}$ can only contain one argument with an unchecked case feature. That SpecTP must be filled is thus constrained by case checking.

19 For brevity, we disregard problems with reflex (nominative) case checking in Chomsky (2001). Let us only remark that the transformation from what Chomsky $(2001: 4,6)$ calls an 'uninterpretable structural Case' to 'nominative' i.e., from ' $\mathrm{u}$-Case' to 'Case $\mathrm{nom}^{\prime} /$ 'NOM' violates the Inclusiveness Principle which, as he himself observes: "bars introduction of new elements (features) in the course of a derivation”. (Chomsky 2001: 2). 
265) argue, for instance, that $\mathrm{T}$ and the verb carry both $\mathrm{T}$ - and $\mathrm{V}$-features and enter into Agree due to their mutually interrelated properties. Verbs carry the uT-feature since they manifest tense morphology, but lack temporal content on their own. $\mathrm{T}$ carries the $\mathrm{uV}$-feature because it lacks the semantics/argument structure of verbs, but is the position where lexical/auxiliary verbs move/are merged. Assuming the above view on the nominative case-feature, $\mathrm{T}$ is also extensional with respect to the nominative DP, allowing it to be interpreted in the TP-domain. It is thus reasonable to assume that T's iT-feature reflects T's inherent Tense-related property and that because of this property, the movement of a uT-feature-bearing category to $\mathrm{T}$ or SpecTP is not mandatory. On the contrary, it is doubtful that $\mathrm{T}$ is inherently nominal. V-to-T movement is irrelevant to subject licensing (Biberauer and Roberts 2010: 267; Roberts 2010; Vangsnes 2002), which necessitates an overt D-/ $\varphi$-features-bearing category in SpecTP (unless, perhaps, in null-subject languages whose verbs may carry D-features). We take this necessity of the movement of an $i \varphi$-feature-bearing item to SpecTP to be due to T's lack of the inherent nominal property manifested formally as $\mathrm{u} \varphi$-features. ${ }^{20}$ Semantically-wise, we follow Vangsnes (2002) and claim that nominal properties must be manifested lexically in SpecTP so that the denotations of the subject and the event expressed by the verb both be anchored to the same state of-affairs. ${ }^{21}$ Essentially, the presence of the subject in SpecTP: (i) - allows the event denotation to be anchored with respect to the verb's thematically most prominent argument (Vangsnes 2002: 60-61); (ii) - allows the subject to be identified as a part of this event denotation/state-of-affairs i.e., ascribed the semantic property of (the temporally modified) VP.

Syntactically then, TP represents an Aristotelian bipartite proposition, a point in the derivation where the subject (DP), rendered as SpecTP, is asserted/denied, with the help of tense, some property by the predicate (VP), rendered as T'. This proposition is schematised in a simplified form in (14) on the basis of example (11) ('ASCR' = 'is ascribed the property of ).

(14)

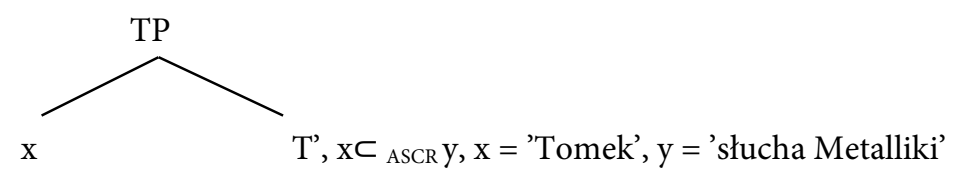

In section 2.2.2 we show that this bipartite structure of proposition also holds of DCCs. Following Rothstein's (2004) approach to predication, we argue against the semantically void verbal copula and motivate this premise by considering the semantic details of predicate

20 Polish DCCs may of course have null subjects. In (i) below, the neighbourhood has already been mentioned in A, so it is salient enough to be left out in B. We disregard such contexts here.

(i) A: Wiesz coś więcej o tej okolicy?

'Do you know more about this neighbourhood?'

B: To byly obrzeża miasta.

'(This neighbourhood) was the outskirts of the city.'

${ }^{21}$ Vangsnes actually refers to SpecAgrSP due to investigating the distribution of different subject types in Icelandic Transitive Expletive Constructions (TECs). In TECs, SpecAgrSP is where expletives sit, with their nominal associates (subjects) located in SpecTP (e.g. Рað hefur verið einhver köttur í eldhúsinu 'There has been some cat in the kitchen'). We follow Vangsnes's (2002) semantic motivation for the subject requirement, but proceed without assuming AgrSP. Nothing hinges on that. 
formation, the corresponding syntactic form it takes, and how these two aspects underlyingly separate $\mathrm{DP}_{1}$ from the verbal copula and its $\mathrm{DP}_{2}$ complement. This will allow us to: (i) - dispense with the predicate raising hypothesis and its predictions with respect to semantics of predicational and specificational DCCs; (ii) - maintain the syntax-semantic primacy of one of the nominative arguments; (iii) - show that the subject requirement as outlined above is uniformly satisfied by the higher nominative DP. ${ }^{22}$

\subsubsection{The EPP-requirement in DCCs: Deriving the bipartite structure of predication}

Consider first the issue of whether być 'to be' contributes semantically to the interpretation of (copular) sentences. Neither Bondaruk $(2019,2013)$ nor Citko (2008) address this issue directly, but syntactic and semantic considerations they offer suggest that they discard such a possibility. ${ }^{23}$ For Benveniste, however, (1966: 159, 162), who examines Latin and Ancient Greek verb-less and verbal copular clauses, the difference between the two exists. The former, like Latin omnia praeclara rara, lit. 'all excellent things [are] rare', lack the 'narrative content' since the nominal predicate introduces no event (cf. Citko 2008, for whom the defective $\pi$ lacks the eventuality variable). It only asserts the very semantic content about the subject, i.e., expresses general statements/states and universal truths which lack temporal determination (cf. Meillet 1906). ${ }^{24}$ This temporal determination crops up in the latter, like Latin omnia praeclara rara sunt, 'all excellent things are rare', where be relates the event time to the speech time, thereby yielding the narration of a situation (Benveniste 1966: 159, 162-163). The same difference also characterises the Polish copular clauses.

(15) Marek to lekarz

Marek-NOM COP doctor-NOM

'Marek is a doctor'

(16) Marek to jest lekarz

Marek-NOM COP is-3-SG doctor-NOM

'Marek is a doctor'

The verb-less one in (15) only informs that there is a property of 'doctorhood' ascribed to Marek by the predicative DP alone. A naïve interpretation of (15) would be that 'Marek has the

22 The predicate raising hypothesis is defined in (i) and yields the semantics of predicational and specificational DCCs as captured in (ii). This hypothesis has been widely advocated by Moro (1997), Zamparelli (2000), Adger and Ramchand (2003), Bondaruk (2012, 2019), amongst others.

(i) specificational DCCs are derived from predicational DCCs by virtue of predicate raising

(ii) specificational DCCs have predicative subjects and referential post-copular DPs; predicational DCCs have referential subjects and predicative post-copular DPs

Syntactic/empirical arguments for predicate raising hypothesis are numerous, but will not be discussed, both for space reasons, and because they do not directly relate to the scrutiny of this paper. See Bondaruk (2013) and Mikkelsen (2005) for details.

${ }^{23}$ This stance is dominant amongst scholars (e.g. Déchaine 1993; den Dikken 2006; Heycock 2013).

${ }^{24}$ We discuss temporal properties of verb-less copular clauses later in this section while scrutinising the status of the word to. 
property of a doctor'. Contrastively, the presence of być in (16), a DCC, locates the semantic content of the predicative DP in a temporally determined eventuality, which yields a proposition asserting that 'there is an event in which it holds (at some time $t$ ) that Marek has the property of doctorhood'. The interpretational disparity between (15) and (16), however subtle it is, suggests that we should not treat być 'to be' as completely semantically void (in this respect, cf. also Partee 1987: 375, 2000, 2010). But even if it is even minimally semantically substantive, Benveniste's remarks do not say why be would form a predicate together with its post-verbal complement. A plausible reason is, however, offered by Rothstein (2004) who, like Benveniste, takes be to introduce a temporally determined eventuality. ${ }^{25,}{ }^{26}$ Unlike him, however, she claims that whilst lexical verbs introduce both the eventuality and its property (e.g. the verb read introduces the event whose property is 'reading'), the verbal copula does not specify the property it introduces. It is only after be combines with its complement like a referential DP (Rothstein 2004: 243-246) or an adjective (ibid. 289-297, 318-326) that we can determine what kind of eventuality it is. To capture Rothstein's idea we may use the fairly simplified logical notations in (17)-(18) (' $\mathrm{P}_{(e)}$ ' = 'property of eventuality'). Expressed in such terms, the complex predicate [być + post-copular complement] in (18) follows from syntaxsemantic considerations, for only a syntactically complex form can denote a fully semantically specified eventuality. Hence, the infelicitous status of examples like (19), where the $\mathrm{DP}_{1}$ subject accompanied only by the verbal copula is not ascribed any property. ${ }^{27}$

(17) $[$ lexical $\operatorname{verb}(e \& \mathrm{P}(e))]$

(18) $\quad\left[\operatorname{verbal}_{\text {copula }(e)}\left[\operatorname{complement}_{(\mathrm{P}(e))}\right]\right]$

(19) ${ }^{*}$ Marek jest

Marek is-3-SG

'Marek is'

${ }^{25}$ She follows a neo-Davidsonian semantics theory (see Parsons 1990), whereby verbs denote event arguments ' $e$ ' and introduce a set of thematic roles (e.g. Agent, Goal) which denote functions from events into individuals. A neo-Davidsonian semantics of Marek napisat artykut 'Marek wrote an article' is given in (i). The existentiallybound event variable $(\exists e)$ represents an expression which denotes the truth value ' 1 ' i.e., 'true' if it holds that $y$ $\subset_{\mathrm{ASCR}}$ to $\mathrm{x}$, where $\mathrm{x}=$ subject and $\mathrm{y}=$ predicate.

(i) $\exists e(\operatorname{WRITE}(e) \& \operatorname{AGENT}(e$, Marek) $\& \operatorname{GOAL}(e$, artykuł) \& $\operatorname{PAST}(e))$

${ }^{26}$ Examining the behaviour of state expressions, Maienborn $(2005,2007,2011,2019)$ shows that sentences with the copula be behave like stative verbs (e.g. know, weigh, cost, own, resemble, etc.) and, hence, unlike state verbs (e.g. sit, stand, lie, wait, gleam, sleep), do not meet the criteria for Davidsonian eventualities. Thus, they cannot serve as infinitival complements of perception verbs, cannot combine with locative modifiers and manner adverbials (Maienborn 2019: 41-43). Instead, they are shown to instantiate Kimian states (Kim 1969, 1976) in that: (i) they are not accessible to direct perception, (ii) have no location in space, (iii) no unique manner of realisation, (iv) can be located in time, (v) are reified entities of thought/discourse, (vi) are closed under complementation $(2019: 47-52)$. See Maienborn $(2011,2019)$ for detailed remarks.

27 Such examples are grammatical but in contexts with ellipted post-copular complements.

(i) Tomek to nie jest lekarz, ale Marek jest.

Tomek COP not is-3-SG doctor, but Marek is-3-SG

'Tomek is not a doctor, but Marek is.' 
Assuming this standpoint, the derivational step marking the establishment of a complex predicate in DCCs will be [Pred'] instantiating the merger of być and its complement. In this respect, consider now the semantics of the predicational DCC from $(16)=(20)$ up to the point where [Pred'] is formed. We use lambda $(\lambda)$ abstraction to account for how the structure is combined and interpreted in the semantics. Since be assigns no thematic roles, we use ' $\mathrm{Arg}_{1}$ ' and 'Arg' ${ }_{2}$ rather than 'Agent' and 'Patient' to annotate external and internal arguments, respectively.

(20) Marek to jest lekarz

Marek COP is-3-SG doctor

'Marek is a doctor'

(21) $[\operatorname{Pred}]: \lambda \mathrm{y} \lambda \mathrm{x} \lambda \mathrm{e}\left[\mathrm{P}(e) \& \operatorname{Arg}_{1}(e)=\mathrm{x} \& \operatorname{Arg}_{2}(e)=\mathrm{y}_{(\mathrm{P}(e))} \& \mathrm{y}=\mathrm{x}\right]^{28}$

(22) $\quad\left[\operatorname{Pred}^{\prime}\right]: \lambda \mathrm{y} \lambda \mathrm{e}\left[\mathrm{P}(e) \& \operatorname{Arg}_{1}(e)=\mathrm{x} \& \operatorname{Arg}_{2}(e)=\mathrm{y}_{(\mathrm{P}(e))} \& \mathrm{y}=\mathrm{x}\right]($ lekarz $)=$

$\lambda$ e [being-a-doctor(s) \& $\operatorname{Arg}_{1}(s)=\mathrm{x} \& \operatorname{Arg}_{2}(s)=\operatorname{lekarz}_{(\mathrm{P}(s))} \&$ lekarz $\left.=\mathrm{x}\right]$

In (21), the proposition from (20) is turned by a $\lambda$-operator into a function represented by the verbal copula być ([Pred]). This function selects the arguments of the proposition and replaces $\left(\lambda\right.$-abstracts) them by variables ' $\mathrm{x}$ ', ' $\mathrm{y}$ ', the latter specifying the property $\mathrm{P}_{(e)}$ of the eventuality introduced by być. At this point, we take the fact that DCCs denote non-eventive assertions in which, at some time $t$, something holds rather than begins/is in progress/culminates, to indicate that both predicative and referential post-copular DPs introduce a state $s$ rather than an event $e$ argument (see Parsons 1990 for discussion; cf. also Bondaruk 2013: 217). For example, in (22), być merges with lekarz 'a doctor', which is interpreted in the semantics as the application of the function to the predicative $\operatorname{Arg}_{2}$. This results in the formation of the predicate [Pred'] whose paraphrase could be: 'an eventuality which instantiates the state of doctorhood'. Predicate formation is defined by Rothstein (2004: 138) as follows.

(23) If $\kappa$ is the translation of a syntactic predicate then $\kappa \rightarrow \lambda x \cdot \kappa^{29}$

In the semantics, $\kappa$ is prefixed by $\lambda x(24)$ which means that the semantic content of $\kappa$ will be applied to the denotation of the referential $\operatorname{Arg}_{1}$.

${ }^{28}$ To account for the predicative use of DPs, Partee (1987) uses the ident operator 'ident: $\lambda \mathrm{y} \lambda \mathrm{x}[\mathrm{y}=\mathrm{x}]$ '. It maps any ' $y$ ' to the property identical to ' $y$ '. When applied to the predicative DP lekarz 'a doctor', it yields $\lambda x[\lambda y$ $[\operatorname{lekarz}(\mathrm{y})]=\mathrm{x}$ so DP thus mapped denotes the property identical to that of a doctor. The notation ' $\mathrm{y}=\mathrm{x}$ ' is simplified for expository reasons.

29 We use $\kappa$ instead of Rothstein's $\alpha$ since here $\alpha=$ Probe. The term 'syntactic' follows from Chierchia (2004) and Rothstein's (1995) considerations, whereby the sentence has a bipartite structure - a function (predicate) and an argument (subject). The function is structurally incomplete and must apply to a complete constituent (argument) to be closed. This idea reverberates Frege (1891/1960), where the 'saturated'/'unsaturated' status is determined by constituents' combinatorial properties (Rothstein 2004: 44). DPs are inherently saturated, for they can stand on their own. VPs are inherently incomplete, as they require DPs to form a sentence (cf. Frege 1891/1960: 31). This requirement is syntactic because it holds regardless of verbs' thematic properties (Rothstein 2004: 44-49). It characterises predicates with lexical verbs (e.g. visited John), the copula be, or raising verbs like seem (e.g. is a tall man and seems that John is late). 
[Pred']: $\lambda \mathrm{x} \lambda$ e [being-a-doctor $(s) \& \operatorname{Arg}_{1}(s)=\mathrm{x} \& \operatorname{Arg}_{2}(s)=\operatorname{lekarz}_{(\mathrm{P}(s))} \&$ lekarz $\left.=\mathrm{x}\right]$

Assuming, as commonly done, that the basic DP order in DCCs is $\mathrm{DP}_{\text {referential }}>$ być $>\mathrm{DP}_{\text {predicative, }}$ the fact that $\kappa$ translates to a syntactic and semantic predicate (to which the predicative $\operatorname{Arg}_{2}$ contributes semantically) implies that $\operatorname{Arg}_{2} \in \kappa$. In this respect, consider now the semantics of [Pred'] in specificational DCCs like (25).

(25) Lekarz to jest Marek

doctor COP is-3-SG Marek

'A doctor is Marek'

(26) $[\operatorname{Pred}]: \lambda \mathrm{y} \lambda \mathrm{x} \lambda \mathrm{e}\left[\mathrm{P}(e) \& \operatorname{Arg}_{1}(e)=\mathrm{x} \& \operatorname{Arg}_{2}(e)=\mathrm{y}_{(\mathrm{P}(e))} \& \mathrm{x}=\mathrm{y}\right]$

(27) [Pred']: $\lambda \mathrm{y} \lambda \mathrm{e}\left[\mathrm{P}(e) \& \operatorname{Arg}_{1}(e)=\mathrm{x} \& \operatorname{Arg}_{2}(e)=\mathrm{y}_{(\mathrm{P}(e))}\right]($ marek $)=$

$\lambda$ e [existence-of-marek(s) \& $\operatorname{Arg}_{1}(s)=\mathrm{x} \& \operatorname{Arg}_{2}(s)=\operatorname{Marek}_{(\mathrm{P}(s)} \& \mathrm{x}=$ Marek]

[Pred']: $\lambda \mathrm{x} \lambda \mathrm{e}$ [existence-of-marek(s) \& $\operatorname{Arg}_{1}(s)=\mathrm{x} \& \operatorname{Arg}_{2}(s)=\operatorname{Marek}_{(\mathrm{P}(s))} \& \mathrm{x}=$ Marek]

In (27), byc merges with Marek, so the function first applies to the referential $\operatorname{Arg}_{2}$ which specifies the property $\mathrm{P}_{(e)}$ of the eventuality introduced by być. ${ }^{30}$ This step results in the formation of [Pred']. Since $\mathrm{Arg}_{2}$ is not used predicatively but refers to an individual, we assume that the denotation of [Pred'] jest Marek 'is Mark' is simply 'an eventuality instantiating the state of existence for Marek'. As in (24), $\kappa$ translates to a syntactic and semantic predicate of which $\operatorname{Arg}_{2}$ is part. In (28), the denotation of $\kappa$ is prefixed by $\lambda \mathrm{x}$ and will apply to the denotation of the predicative $\operatorname{Arg}_{1}$.

Considering this semantics-based scrutiny we observe that $\kappa$ in (24) and (28) is not the same. The 'predicational $\kappa$ ' (which we label $\varepsilon$ ) predicates of the referential $\mathrm{DP}_{1}$, and the 'specificational $\kappa$ ' (which we label $\rho$ ) specifies the value for the variable set up by the predicative $\mathrm{DP}_{1}$. This means that the predicative DPs in (24) and (28) are not the same either, for the one in the predicative DCC is syntactically and semantically part of $\varepsilon$ which predicates of the referential DP, and the one in the specificational DCC is specified by $\rho$ of which the referential $\mathrm{DP}$ is now part. This difference cannot come from predicate raising, for given the underlying word order $\mathrm{DP}_{\text {referential }}>$ być $>\mathrm{DP}_{\text {predicative, }} \mathrm{DP}_{\text {predicative }}$ cannot be specified by $\rho$, where $\rho=b y \dot{c}+$ $\mathrm{DP}_{\text {referential }}$ if $\mathrm{DP}_{\text {predicative }} \in \varepsilon, \varepsilon=b y c+\mathrm{DP}_{\text {predicative }}$ and the formation of $\varepsilon$ is the initial derivational step of a DCC. The difference must thus arise from the order at which the function applies to arguments, which, in turn, suggests that the predicative DP in (25) is base-generated in SpecPredP just as the referential DP in (20). This is summarised in (29)-(30). We conclude that the formation of $\varepsilon$ and $\rho$ does not take place within the same derivation, but implicates two different derivations.

(29) $\mathrm{DP}_{\text {referential }}$ is in SpecPredP: 'predicated of' (by $\varepsilon, \varepsilon=b y c$ ' $\left.+\mathrm{DP}_{\text {predicative }}\right)$

(30) DP $P_{\text {predicative }}$ is in SpecPredP: 'specified' (by $\rho, \rho=b y c ́+\mathrm{DP}_{\text {referential }}$ )

${ }^{30}$ In compliance with (20), ' $\mathrm{P}_{(e)}$ ' always comes from the $\mathrm{DP}_{2}$ complement, regardless of whether it is used predicatively or referentially. 
Taking these considerations into account, we claim, contra Bondaruk $(2019,2013)$, that the subject requirement in Polish DCCs only holds of the nominative $\mathrm{DP}_{1}$. We now move on to determine the status/role of the word to and the derivational step at which $\kappa$ applies to $\mathrm{x}$. We discuss these issues in the respective order.

As already indicated (section 1, fn.6), the status of the particle to is vague and different scholars consider it from various standpoints. For example, Rutkowski (2006) (but cf. also Hentschel 2001) defines to as a demonstrative pronoun located in SpecTP, with DP 1 basegenerated in the left periphery (SpecTopP) and $\mathrm{DP}_{2}$ functioning as a VP-internal subject. For Tajsner (2015a, 2015b), to functions as a focus marker, heading the Specification Predication Phrase (S-PredP). As noted earlier (fn.1), Błaszczak and Geist (2001) consider to a conjunctionlike particle. They also take it to project its own ètoP projection (they examine both Polish and Russian), thereby linking two elements (one in SpecetoP and the other as the complement of to). Here, we basically follow Bondaruk $(2019,2013)$ in that to represents a pronominal copula with clitic-like properties owing to which it shows distributional patterns as in (31)-(32), these being, perhaps, subject to some PF-movement constraints (cf. Bondaruk 2013: 234-240).

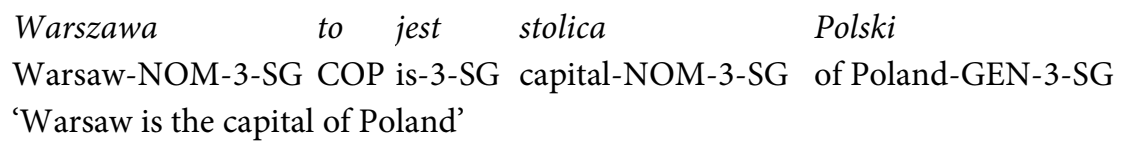

Contra Bondaruk, however, we do not place it in Pred, but base-generate in $\mathrm{T}$, the choice following from the distribution of to and być 'to be' in DCCs. As (33)-(34) show, to is obligatory in past, present, and future tense DCCs, whereas być can be dropped in the present tense DCCs, the fact annotated by placing it in brackets in (33).

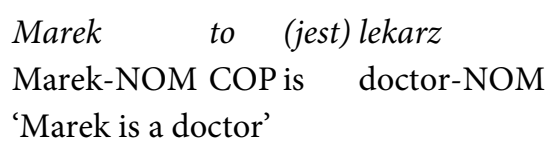

Suppose then, that past and future tense DCCs carry the past and the future tense specified for the categorial verbal $[+\mathrm{V}]$ and nominal $[+\mathrm{D}]$ features and, hence, the obligatory presence of both copulas in (34). Contrastively, present tense DCCs carry the present tense feature which does not require the $[+\mathrm{V}]$ feature and may be satisfied by the nominal item alone. This allows for copular clauses with only the pronominal copula like in (15) above. Similar considerations have been followed (e.g. Alharbi 2017; Benmamoun 2000, 2008; Doron 1986) to account for Hebrew and Arabic present tense copular clauses. Benmamoun (2008: 125), for example, takes the Hebrew pronominal copula (which agrees with the subject in number and gender but lacks any tense marking) to be the manifestation of the present tense's nominal feature whose 
specification is, accordingly, $[+\mathrm{D}$, number, gender $] .{ }^{31}$ We argue that to plays the same role in Polish copular clauses. It manifests the present tense's nominal feature whose formal guise is simply $[+\mathrm{D}]$ because to lacks any kind of agreement morphology. ${ }^{32}$ The proposal that to is implicated in feature valuation with $\mathrm{T}$ has three major benefits. First, since to remains a nominal item, we can still account for its clitic-like properties and distribution in examples like (33)(34). Second, the location of to is no longer problematic, even considering its lack of tense morphology, an issue raised by Bondaruk (2019: 117). Third, the temporal property of verb-less copular clauses like (15) receives a straightforward explanation. The present tense has only the nominal feature to value (but cf. fn.32), so it requires no verbal item/morphology to convey the present tense interpretation. ${ }^{33}$ But because $\mathrm{T}$ does not have to be paired with a verbal head or other temporal markers, examples like (15) lack an unambiguously located temporal reference.

Finally, let us account for the ascription of $\kappa$ 's denotation to the subject. We have already suggested (section 2.2.1), that TP is where the proposition is encoded configurationally between the subject (in SpecTP) and the predicate ( $\left.\mathrm{T}^{\prime}\right)$. Assume then, that after $\mathrm{DP}_{1}$ merges with [Pred'] it yields [PredP] which is too small a domain for establishing proposition. ${ }^{34}$ It is only when [PredP] merges with $\mathrm{T}$ that $\mathrm{\kappa}$ is temporally modified and can be applied to the denotation of the subject. We take this temporal modification to have a syntax-semantic guise. In the semantics, $\mathrm{T}$, a modifier of type $\langle\kappa, \kappa\rangle$, takes as its complement the predicate [Pred'] and returns the same predicate [Pred'], but whose eventuality is now modified by tense. Adopting Biberauer and Roberts's (2010) T-verb Agree relation, we take the syntactic reflex of this modification to be the valuation of the verb's uT-feature by T's iT-feature, which provides the verb with temporal content. The denotation of this temporally modified $\kappa$ is ascribed/applied to $\mathrm{DP}_{1}$ once it occupies SpecTP. Examples (35)-(37) show, in the respective order, the formation of $\kappa$, its temporal modification by $\mathrm{T}$, and the ascription of its denotation to $\mathrm{DP}_{1}$ which has moved to SpecTP in the predicational DCC. Examples (38)-(40) show the same for the specificational DCC.

${ }^{31}$ Similarly to Polish, Hebrew (i) and Arabic (ii) present tense copular clauses may do without the verbal copula. Interestingly, they may also do without the pronominal copula (indicated by brackets). In such cases, Benmamoun takes the nominal feature of the present tense to be valued by the subject.

(i) dani (hu) rofe

Dani SG-MASC doctor

'Dani is a doctor'

(ii) Zayd-un (huwa) l-malik-u

Zayd-NOM he the-king-NOM

'Zayd is the king'

${ }^{32}$ More adequately, given the optionality of być, the present tense feature in DCCs is $[+\mathrm{D},(+\mathrm{V})]$. The $[+\mathrm{D}]$ feature is adopted for simplicity given the troublesome categorial status of the word to.

${ }_{33}$ Bondaruk (2019: 111) acknowledges that dropping the past/future verbal copula in DCCs like (34) triggers the present tense interpretation, but she does not correlate this fact with the presence/properties of $t$.

${ }^{34}$ In Aristotelian terms, a sentence affirms/denies the subject's predicate once it features the subject, the predicate, and tense, the three resulting in a proposition (Woodard 2018: 43). 
(35) $\quad[\operatorname{PredP}]: \lambda \mathrm{x} \lambda$ e [being-a-doctor $(s) \& \operatorname{Arg}_{1}(s)=\mathrm{x} \& \operatorname{Arg}_{2}(s)=\operatorname{lekarz}_{(\mathrm{P}(s))} \&$ lekarz $\left.=\mathrm{x}\right](\mathrm{x})=$ $\lambda$ e [being-a-doctor $(s) \& \operatorname{Arg}_{1}(s)=\mathrm{x} \& \operatorname{Arg}_{2}(s)=\operatorname{lekarz}_{(\mathrm{P}(s))} \&$ lekarz $\left.=\mathrm{x}\right]^{35}$

(36) $\quad\left[\mathrm{T}^{\mathrm{T}} \mathrm{T} \operatorname{PredP}\right]: \lambda \mathrm{x} \lambda \mathrm{e}\left[\right.$ being-a-doctor $(s) \& \operatorname{Arg}_{1}(s)=\mathrm{x} \& \operatorname{Arg}_{2}(s)=\operatorname{lekarz}_{(\mathrm{P}(s))} \&$ lekarz $\left.=\mathrm{x} \& \operatorname{Present}(s)\right]$

(37) [тр $\mathrm{x}\left[\mathrm{T}, \mathrm{T}\right.$ PredP]: $\lambda \mathrm{x} \lambda$ e [being-a-doctor $(s) \& \operatorname{Arg}_{1}(s)=\mathrm{x} \& \operatorname{Arg}_{2}(s)=\operatorname{lekarZ}_{(\mathrm{P}(s))} \&$ lekarz $\left.=\mathrm{x} \& \operatorname{Present}(s)\right]$ $($ marek $)=$

$\exists$ e [being-a-doctor $(s) \& \operatorname{Arg}_{1}(s)=\operatorname{Marek} \& \operatorname{Arg}_{2}(s)=\operatorname{lekarZ}_{(\mathrm{P}(s))} \&$ lekarz $=$ Marek \& Present $\left.(s)\right]$

(38) [PredP]: $\lambda \mathrm{x} \lambda$ e [existence-of-marek(s) $\left.\& \operatorname{Arg}_{1}(s)=\mathrm{x} \& \operatorname{Arg}_{2}(s)=\operatorname{Marek}_{(\mathrm{P}(s))} \& \mathrm{x}=\operatorname{Marek}\right](\mathrm{x})=$ $\lambda$ e [existence-of-marek(s) \& $\left.\operatorname{Arg}_{1}(s)=\mathrm{x} \& \operatorname{Arg}_{2}(s)=\operatorname{Marek}_{(\mathrm{P}(s))} \& \mathrm{x}=\operatorname{Marek}\right]$

(39) $\left[{ }_{\mathrm{T}} \mathrm{T}\right.$ PredP]: $\lambda \mathrm{x} \lambda \mathrm{e}$ [existence-of-marek $\left.(s) \& \operatorname{Arg}_{1}(s)=\mathrm{x} \& \operatorname{Arg}_{2}(s)=\operatorname{Marek}_{(\mathrm{P}(s))} \& \mathrm{x}=\operatorname{Marek} \& \operatorname{Present}(s)\right]$

(40) [тр $\mathrm{x}\left[\mathrm{T}^{\mathrm{T}} \mathrm{T}\right.$ PredP]: $\lambda \mathrm{x} \lambda$ e [existence-of-marek $\left.(s) \& \operatorname{Arg}_{1}(s)=\mathrm{x} \& \operatorname{Arg}_{2}(s)=\operatorname{Marek}_{(\mathrm{P}(s))} \& \mathrm{x}=\operatorname{Marek} \& \operatorname{Pres}(s)\right]$ $($ lekarz $)=$

$\exists$ e [existence-of-marek $(s) \& \operatorname{Arg}_{1}(s)=\operatorname{lekarz}_{2} \operatorname{Arg}_{2}(s)=\operatorname{Marek}_{(\mathrm{P}(s))} \&$ lekarz $\left.=\operatorname{Marek} \& \operatorname{Present}(s)\right]$

The movement of the higher nominative DPs to SpecTP makes it ascribed the semantic content of T' i.e., the temporally modified $\kappa$. This, as shown in section 2.2 .1 , is a configuration which produces the proposition whereby the denotations of the DP subject and T' are anchored to the same state-of-affairs. This is manifested semantically by the existential binding of eventuality variables $(\exists e)$ of expressions denoted in (37) and (40) owing to which they receive the value 'true', namely, they are asserted the property denoted by $\mathrm{T}$ '.

Section 2.2.3 below briefly outlines the derivation of Polish predicational and specificational DCCs on the basis of the considerations from sections 2.2.1 and 2.2.2.

\subsubsection{The EPP in DCCs: A revised formal account}

For the sake of examination, we use examples (1)-(2) which Bondaruk (2019) uses in her own analysis of DCCs. The two examples are repeated below in (41)-(42). For convenience, we also repeat Zeiljstra's (2012) upward Agree (43).

(41) Ta okolica to byty obrzeża miasta this neighbourhood-NOM-3-SG-FEM COP were-3-PL-N-VIR outskirts-NOM-3-PL-NEUT of-city 'This neighbourhood was the outskirts of the city'

Obrzeża miasta to była ta okolica

outskirts-NOM-3-PL-NEUT of-city COP was-3-SG-FEM this neighbourhood-NOM-3-SG-FEM

'The outskirts of the city were this neighbourhood'

(43) Agree: $\alpha$ can Agree with $\beta$ iff:

a. $\alpha$ carries at least one uninterpretable feature and $\beta$ carries a matching interpretable feature.

b. $\beta$ c-commands $\alpha$.

c. $\beta$ is the closest goal to $\alpha$.

35 The arguments Marek and lekarz are interpreted in SpecTP, so the function in (35) and (38) applies to the variables they leave behind in SpecPredP. Once the two arguments are identified in SpecTP (examples (37) and (40), respectively), the variables are replaced by the denotations of Marek and lekarz. 
Let us now examine the derivation of the predicational DCC (41) at the moment when PredP merges with $\mathrm{T}$, producing $\mathrm{T}$ '.

(44)

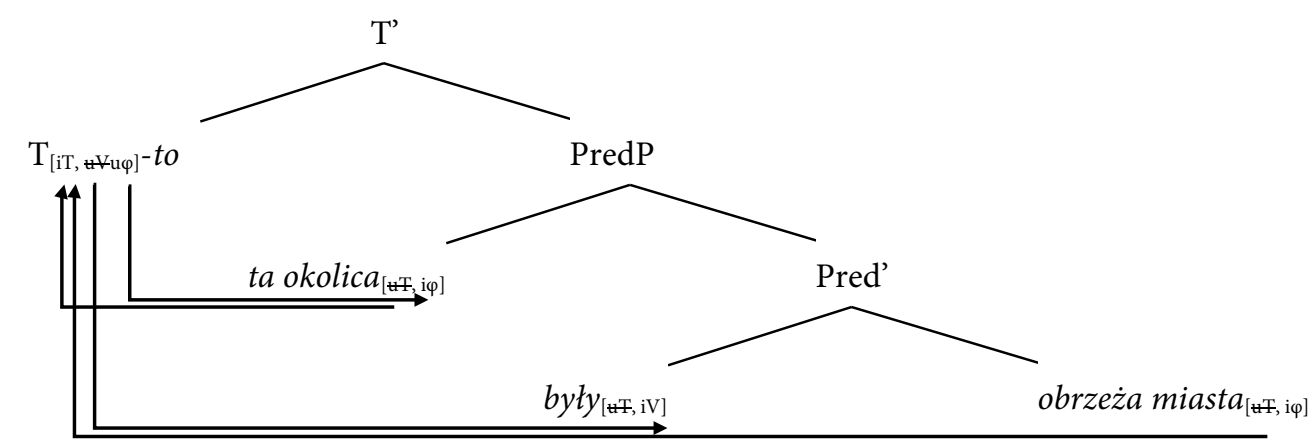

As shown in (44), the Agree relation between $\mathrm{T}$ and the verbal copula byty 'were' follows in a 'classic' manner. This is because it does not involve DP with i $\varphi$-features and the uT-feature, and so it does not satisfy the subject requirement. Consequently, $\mathrm{T}$ probes down to have its $\mathrm{uV}$ feature valued by the iV-feature which it locates on the copula (Goal). As a result of this Agree relation, the copula's uT-feature is also valued by T's iT-feature (Biberauer and Roberts 2010: 265, 270), which makes [Pred'] temporally modified. On the other hand, the Agree relation between T and DPs ta okolica 'this neighbourhood' and obrzeża miasta 'the outskirts of the city' follows in an upward manner. This is because it is expected to satisfy the subject requirement, for it takes place between T and DP with the [i $\varphi, u T]$ featural matrix. Since in (44) two DPs carry the uT-feature, by virtue of (43a) both function as Probes and probe upwards to have their features valued by the iT-feature which they locate on T (Goal). Since at this step in all Agree instances between $\mathrm{T}$ and the two DPs the iT-feature c-commands the uT-features, no movement of a uT-feature bearing item to SpecTP is required for Agree to take place. This follows from the inherent Tense-related property of $\mathrm{T}$ (see section 2.2.1). As for the multiple valuation of DPs' uT-features, it yields no relativised minimality effects (contra Bondaruk 2019), for being initiated by DPs and not by T, no alternative Goal intervenes between multiple Probes. Multiple Agree thus proceeds with no additional assumptions. The next step involves the valuation of T's u $\varphi$-features. By virtue of (43a), this valuation is initiated by T and since T's property is not inherently nominal (see section 2.2.1), it necessitates the movement of the $i \varphi$ features-bearing item to SpecTP. Notice that despite the fact that both Bondaruk (2019) and the present approach take $\mathrm{DP}_{1}$ to move to SpecTP in predicational DCCs, only in (44) does the movement of $\mathrm{DP}_{1}$ receive a principled explanation. First, it moves because it is the only legitimate $\mathrm{DP}$ to move $\left(\mathrm{DP}_{2}\right.$ is syntactically and semantically part of the complex predicate [Pred']). Second, it moves so that Agree between it and T may take place and this is only possible when DP's i $\varphi$-features c-command T's u $\varphi$-features. The movement thus satisfies (43c). It is shown by dotted lines in (45). Having moved there, the subject DP is lexically identified in TP, which makes its denotation and the denotation of the predicate anchored to the same state-ofaffairs. This is schematised in (46), where the subject is ascribed the semantic content of the temporally modified [Pred'] $(\varepsilon)$. This step results in the formation of the proposition that asserts that there is an eventuality in which the state of being city outskirts holds of the specific neighbourhood. 
$(45)$

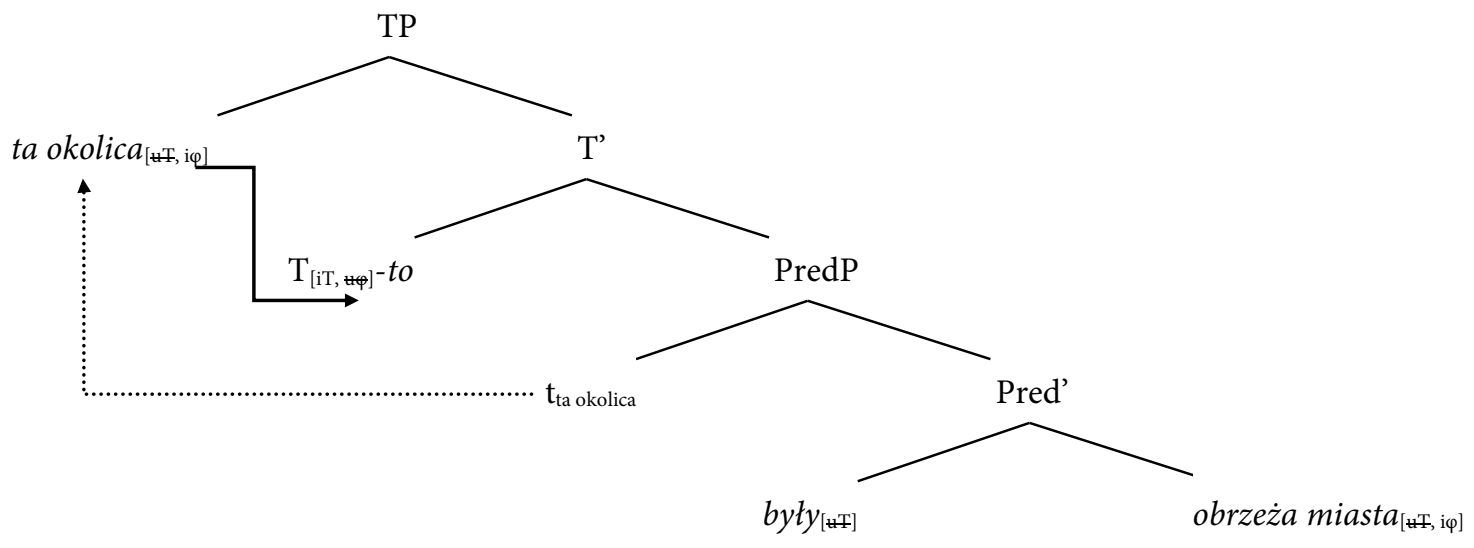

(46)

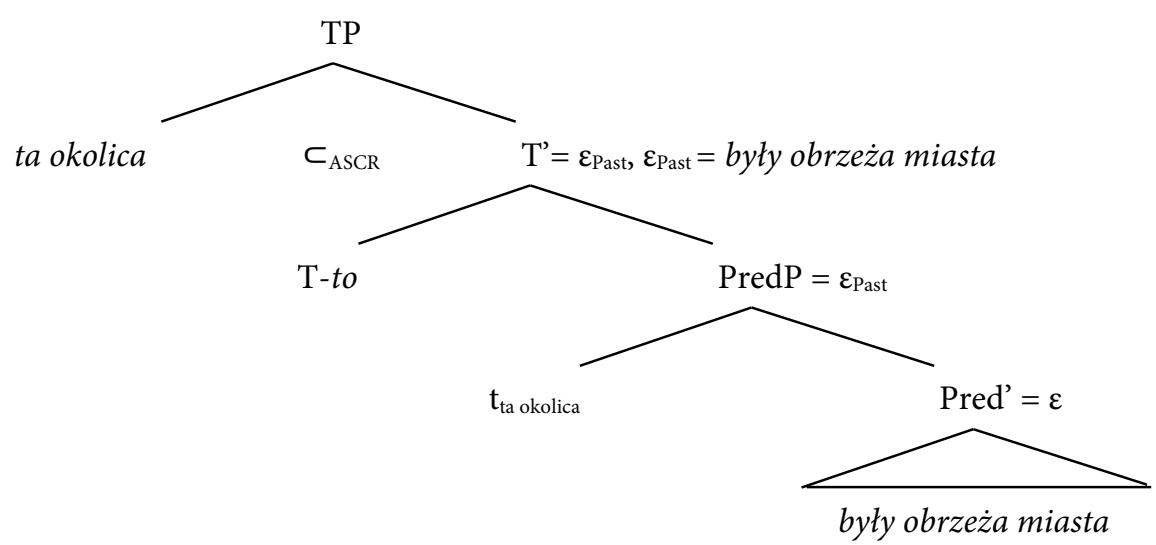

The same constraints apply to specificational DCCs like (42). The Agree relation between T and the verbal copula follows downwards for it does not satisfy the subject requirement. $T$ thus

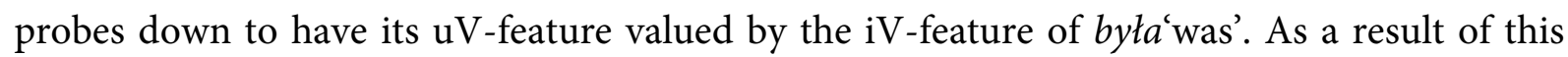
Agree, była 'was' also has its uT-feature valued by T's iT-feature. The Agree between T and the two DPs follows upwards, for it involves DPs with the [i $\varphi, \mathrm{uT}]$ featural matrix and, hence, is expected to satisfy the subject requirement. By virtue of (43a), the two DPs which carry the uTfeatures probe upwards to have them valued against T's iT-feature. As in (44), the iT-feature ccommands uT-features so Agree is satisfied without resorting to movement. No relativised minimality effects follow either since no alternative Goal intervenes between the two DP Probes. This multiple Agree procedure is shown in (47). The next instance of Agree involves the valuation of T's $\mathrm{u} \varphi$-features which, by virtue of (43a), is initiated by T. Since T's property is not inherently nominal, it necessitates the movement of DP to SpecTP. As in (44), and in contradistinction to Bondaruk (2019), only $\mathrm{DP}_{1}$ is legitimate to move, for $\mathrm{DP}_{2}$ is syntactically and semantically part of [Pred']. ${ }^{36}$

\footnotetext{
${ }^{36}$ Notice that the valuation of the uTopic-feature carried by the predicative $\mathrm{DP}_{1}$ is now also unproblematic, for not only is there no relativised minimality effects, but also no feature-tandem phenomenon is necessary to move the predicative $\mathrm{DP}_{1}$ to SpecTP. Its movement now stems directly from (43a-c).
} 


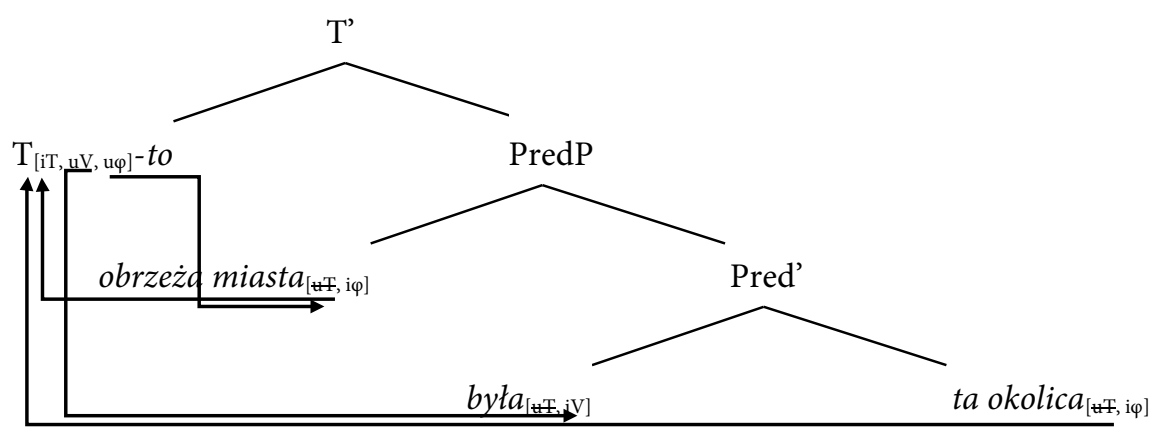

Having moved to SpecTP, the DP obrzeża miasta is lexically identified in TP and the denotations of this DP and that of the predicate are anchored to the same state-of-affairs. This is shown in (48), where the subject is ascribed the semantic content of the temporally modified [Pred'] $(\rho)$. This step, as in the case of the predicational DCC, results in the formation of the proposition which asserts that there is an eventuality in which the existence of the specific neighbourhood determines of whom the property of city outskirts holds.

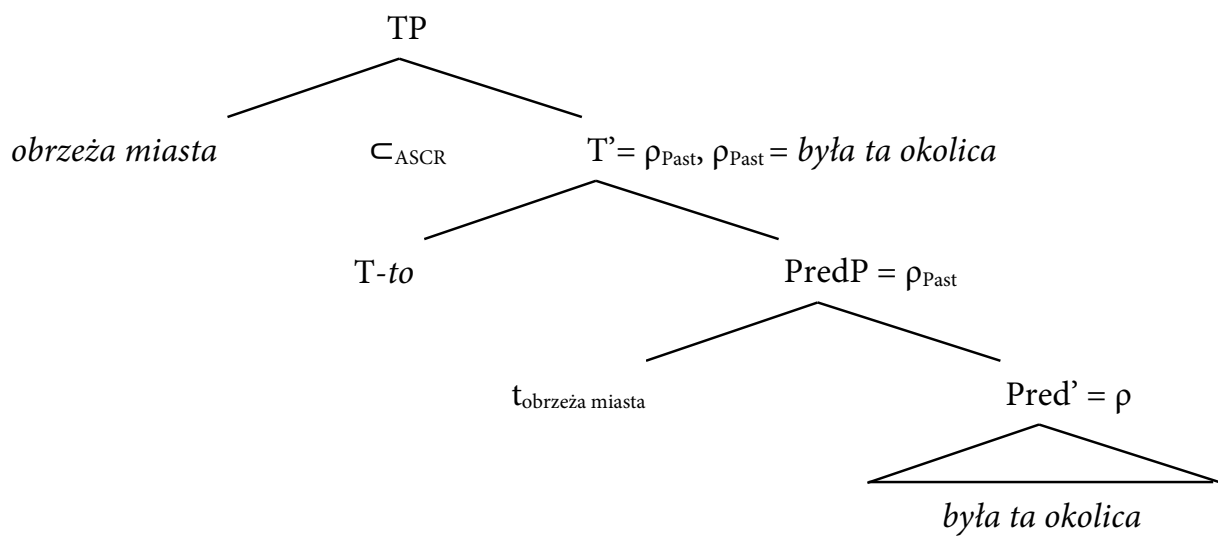

Given the above considerations, the troublesome EPP-feature becomes redundant, for the requirement that SpecTP be lexically occupied is now formally motivated. It holds to compensate for T's lack of the inherent nominal property rendered formally as $u \varphi$-features. $T$ must then probe for the $i \varphi$-features of DP, which necessitates the movement of DP to SpecTP. This creates the configuration where DP's $i \varphi$-features c-command T's $u \varphi$-features so that: (i) Agree between the two may take place; (ii) - the denotation of the temporally modified [Pred'] can be ascribed to DP in SpecTP. Furthermore, the subject requirement is now constrained. It can only probe for the $\mathrm{i} \varphi$-features of the closer $\mathrm{DP}\left(\mathrm{DP}_{1}\right)$ because $\mathrm{DP}_{2}$ (in both predicational and specificational DCCs) is syntactically and semantically part of the complex predicate [Pred'] whose semantic content is ascribed to the denotation of $\mathrm{DP}_{1}$ once the latter lands in SpecTP. The derivation outlined here also holds of predicational (49) and specificational (50) DCCs featuring $1^{\text {st }}$ and $2^{\text {nd }}$ person pronouns in which $\varphi$-agreement is determined by the person hierarchy (51)-(52) (Bondaruk 2019: 126). ${ }^{37}$

${ }^{37}$ The issue of what motivates the person hierarchy in DCCs is not relevant for this scrutiny and will be omitted. 
My to jesteśmy złodzieje

We-1PL-NOM COP are-1PL thieves-3PL

'We are thieves.'

(50) Szczęściarz to jesteś ty

lucky man-3SG-NOM COP are-2SG you-2SG-NOM

'A lucky man is you.'

(51) If $\mathrm{NP}_{1}$ is $1^{\text {st }}$ or $2^{\text {nd }}$ person, then it can and will agree thereby blocking $\mathrm{NP}_{2}$ agreement.

(52) Only if $\mathrm{NP}_{1}$ is $3^{\text {rd }}$ person, will $\mathrm{NP}_{2}$ agreement be possible.

In (49)-(50) nothing changes as regards the binary structure of proposition. $\mathrm{DP}_{1}$ is invariably expected to move to SpecTP because $\mathrm{DP}_{2}$ is semantically and syntactically part of [Pred']. What changes only is the way $\varphi$-features valuation operates (see immediately below). ${ }^{38} \mathrm{~W}$ ith respect to the above, Bondaruk's (2019) approach to the derivation of Polish DCCs not only fails to provide a coherent syntax-semantic rendition of the subject requirement, but also leaves the reason for the satisfaction of the subject requirement by two different DPs unaccounted for. On the basis of considerations from sections 2.2.2 and 2.2.3, we conclude that it should, therefore, be rejected on both formal and semantic grounds. Before we conclude our examination, let us briefly discuss two issues which require additional comments in terms of the approach adopted here.

The first issue concerns agreement in DCCs with two nominative $3^{\text {rd }}$ person DPs which is always controlled by $\mathrm{DP}_{2}$. In our approach, such an agreement cannot come from Agree in $\varphi$ features between $\mathrm{T}$ and $\mathrm{DP}_{2}$, for it is $\mathrm{DP}_{1}$ which moves to SpecTP and values $\mathrm{T}$ 's $\mathrm{u} \varphi$-features. But dispensing, as we have done, with Chomsky's (2001) case checking as a reflex of $\varphi$-features valuation, allows for an alternative. Since the nominative case feature is the uT-feature, the verbal copula need not be defective and can have a full set of $\mathrm{u} \varphi$-features. We propose that having them, it acts as a Probe and values them against $\mathrm{DP}_{2}$ 's $i \varphi$-features, which yields $\varphi$ agreement controlled by $\mathrm{DP}_{2}$ in (41)-(42). We thus end up with two $\varphi$-features Agree relations (between T-DP 1 and Pred-DP ${ }_{2}$ ) which serve different formal needs. We surmise that these two relations are necessitated formally because DCCs feature two nominative $3^{\text {rd }}$ person DPs which are both potential subjects expected to engage in operations that yield 'subject effects' i.e., SpecTP-movement and subject-verb agreement. The latter is thus 'taken care of by $\varphi$ agreement between the copula and $\mathrm{DP}_{2}$ and the former emerges due to $\varphi$-agreement between $\mathrm{T}$ and $\mathrm{DP}_{1}$. This scenario also holds of DCCs with $3^{\text {rd }}$ person $\mathrm{DP}_{1}$ (e.g. (50)), although here it results from the person hierarchy (cf. (51)-(52)). In DCCs with $1^{\text {st }}$ or $2^{\text {nd }}$ person $\mathrm{DP}_{1}$ (e.g. (49)) the person hierarchy predicts that the two subject effects will crop up due to $\varphi$-agreement between $\mathrm{T}$ and $\mathrm{DP}_{1}$ only. In such cases, we follow Bondaruk (2019) and Citko, claiming that być 'to be' is defective, thereby lacking $\varphi$-features.

${ }^{38}$ For Bondaruk (2019), in (49) the satisfaction of the EPP-requirement and T's $\varphi$-features valuation are performed by $\mathrm{DP}_{1}$ and in (50) they are divorced, $\mathrm{DP}_{2}$ satisfying the former and $\mathrm{DP}_{1}$ the latter. Her account thus continues with formal shortcomings from the analysis of DCCs with two nominative $3^{\text {rd }}$ person DPs (section $1)$. 
The second issue concerns the very legitimacy of postulating upwards Agree, an odd man out which holds exclusively of the finite $\mathrm{T}$ and the nominative $\mathrm{TP}$, just to account for the fact that SpecTP must be occupied. Nevertheless, such a postulation is nothing else than the EPPrequirement, only motivated and constrained by syntax-semantic considerations. In Chomsky (2001: 4), for instance, it is T's EPP-feature that allows DP to move to Spec of T. The satisfaction of the EPP-feature is thus dependent on the spec-head relation obtained by moving the nominative DP to SpecTP (cf. also Lasnik 2001: 357). In the present approach, the same spechead relation has to be maintained so that Agree between $\mathrm{T}$ and the nominative DP takes place. Here, however, it is not T's EPP-feature, but its $\mathrm{u} \varphi$-features that necessitate the movement of the $i \varphi$-features-bearing item. Making the subject requirement dependent on the valuation of $\varphi$ features, apart from motivating it formally, also has another advantage. It allows us to correlate it with the very syntax-semantic prominence of the nominative argument which, as Haider (2016: 26) observes, is the defining property of SVO languages. Because the nominative argument in languages like Polish or English must be confined to a functional position in a functional projection above $v \mathrm{P}$, Agree between $\mathrm{T}$ and the nominative DP operates upwards, thereby receiving a natural and principled explanation. ${ }^{39}$

\section{Concluding remarks}

This paper shows that the satisfaction of the EPP/subject requirement in Polish DCCs as based on downward and selective multiple Agree, the relational notion of predication and the EPPfeature is formally and semantically untenable. It results in a number of problematic phenomena (e.g. the satisfaction of T's EPP- and $u \varphi$-features by two different DPs or multiple valuation of DPs' u-case features as nominative by $\mathrm{T}$ ) which conspire to a purely configurational rendition of the EPP requirement. Its satisfaction not only lacks formal motivation and requires additional assumptions to bypass locality conditions such as Defective Intervention Constraint and Relativised Minimality, but also leaves the distribution of two nominative DPs unaccounted for.

The novel proposal advanced here argues for a simpler and more straightforward rendition of the subject requirement in Polish DCCs which is satisfied not by the EPP-feature, but by upward Agree between T and the pre-copular nominative DP. This Agree operation only takes place once DP's $i \varphi$-features c-command T's $u \varphi$-features, the proposal motivated by semantic properties of and relations between the finite $\mathrm{T}$, the subject $\mathrm{DP}$ and the $v \mathrm{P} / \mathrm{VP}$ predicate. As a follow-up to this, the post-copular nominative DP is taken to form, together with the verbal copula być 'to be', a complex predicate separated syntactically and semantically from the precopular nominative DP. The validity of this idea is substantiated by a detail-oriented semanticsbased examination of the derivation of DCCs.

We thus end up with a bipartite structure of proposition, whereby the subject (pre-copular nominative DP) in SpecTP is necessarily ascribed the semantic property of T', the tensed

\footnotetext{
${ }^{39}$ In SOV/VSO languages where the obligatory pre-verbal subject position appears to be missing (e.g. Haider 2015; McCloskey 1996), Agree between T and the nominative DP would proceed in a downward fashion or, in the absence of the subject (e.g. in Irish subject-less clauses - see McCloskey 1996), would not take place at all.
} 
predicate (być + post-copular nominative DP). SpecTP-movement and the subject requirement are thus rendered as two sides of the same coin and both receive formal and semantic motivation. Also, the subject requirement is now constrained, being invariably satisfied by the higher (pre-copular) nominative DP. This is due to the fact that the post-copular nominative DP is syntactically and semantically part of the complex predicate and, hence, illegitimate to occupy the subject position in SpecTP. As a result, locality conditions on movement are satisfied without recourse to additional assumptions.

\section{References}

Adger, D., and G. Ramchand. 2003. Predication and equation. Linguistic Inquiry 34: 325-360.

Al-Horais, N. 2013. The minimalist program and its new insight to the concept of universal grammar. Journal of Universal Language 14(2): 79-112.

Alboiu, G. 2000. The features of movement in Romanian. Ph.D. diss., University of Manitoba.

Alexiadou, A., and E. Anagnostopoulou. 2001. The subject in situ generalization, and the role of case in driving computations. Linguistic Inquiry 32: 193-231.

Alexiadou, A., and E. Anagnostopoulou. 2007. The subject in situ generalization revisited. In H.-M. Gärtner and U. Sauerland (eds.), Proceedings of the Workshop on Interfaces + Recursion = Language?, 31-60. Berlin: Mouton de Gruyter.

Allharbi, B. Y. 2017. The syntax of copular clauses in Arabic. Ph.D. diss, University of Wisconsin-Milwaukee.

Benmamoun, E. 2000. The feature structure of functional morphology: Problems of projection representation and derivation. Ph.D. diss, University of Southern California, Los Angeles.

Benmamoun, E. 2008. Clause structure and the syntax of verbless sentences. In R. Freidin, C. P. Otero and M. L. Zubizarreta (eds.), Foundational issues in linguistic theory, 105-131. Cambridge: The MIT Press.

Benveniste, É. 1966. Problèmes de linguistiquegénérale, Vol.1.Paris: Gallimard.

Biberauer, T., and I. Roberts. 2010. Subjects, tense and verb-agreement. In T. Biberauer, A. Holmberg, I. Roberts and M. Sheehan (eds.), Parametric variation: Null subjects in minimalist theory, 263-302. Cambridge: Cambridge University Press.

Błaszczak, J., and L. Geist. 2000. Kopulasätze mit den pronominalen Elementen to/èto im Polnischen und Russischen. ZAS Papers in Linguistics: 115-139.

Błaszczak, J., and L. Geist. 2001.Zur Rolle des Pronomens to/èto in spezifizierenden Kopulakonstruktionen im Polnischen und Russischen. In G. Zybatow, U. Junghanns, U. Mehlhorn, and L. Szucsich (eds.), Current issues in formal Slavic linguistics (Linguistik International 5), 247-257. Frankfurt am Main: Peter Lang.

Boeckx, C. 2008. Bare syntax. Oxford: Oxford University Press.

Bondaruk, A. 2013. Copular clauses in English and Polish: structure, derivation and interpretation. Lublin: Wydawnictwo KUL.

Bondaruk, A. 2014. Characterizing and defining predicational clauses in Polish. In L. Veselovská and M. Janebová (eds.), Complex visible out there. Proceedings of the Olomouc Linguistics Colloquium 2014: Language Use and Linguistic Structure, 333-348. Olomouc: Palacký University.

Bondaruk, A. 2019. Agreement with the post-verbal DP in Polish dual copula clauses. In M. J. Arche, F. Antonio and R. Marín (eds.), The grammar of copulas across languages, 107-129. Oxford: Oxford University Press.

Bošković, Ž. 1997. The syntax of nonfinite complementation: An economy approach. Cambridge: The MIT Press. Bošković, Ž. 2002. A-movement and the EPP. Syntax 5(3): 167-218.

Bowers, J. 1993. The syntax of predication. Linguistic Inquiry 24: 591-656.

Chierchia, G. 2004. A semantics for unaccusatives and its syntactic consequences. In A. Alexiadou, E. Anagnostopoulou and M. Everaet (eds.), The unaccusativity puzzle. Explorations of the syntax-lexicon interface, 22-59. New York: Oxford University Press.

Chomsky, N. 1981. Lectures on government and binding: The Pisa lectures. Holland: Foris Publications. 
Chomsky, N. 1982. Some concepts and consequents of the theory of government and binding. Cambridge: The MIT Press.

Chomsky, N. 1995. The minimalist program. Cambridge: The MIT Press.

Chomsky, N. 2000. The minimalist inquiries. In R. Martin, D. Michaels and J. Uriagereka (eds.), Step by step. Essays on minimalist syntax in honor of Howard Lasnik, 89-155. Cambridge: The MIT Press.

Chomsky, N. 2001. Derivation by phase. In M. Kenstowicz (ed.), Ken Hale: A life in language, 1-52. Cambridge: The MIT Press.

Chomsky, N. 2008. On phases. In R. Freidin, C. P. Otero and M. L. Zubizarreta (eds.), Foundational issues in linguistic theory, 133-166. Cambridge: The MIT Press.

Citko, B. 2008. Small clauses reconsidered: Not so small and not all alike. Lingua 118: 261-295.

den Dikken, M. 2006. Relators and linkers: The syntax of predication, predication inversion, and copulas. Cambridge: The MIT Press.

Déchaine, R-M. 1993. Predicates across categories: Towards a category-neutral syntax. Ph.D. diss, Amherst, University of Massachusetts.

Doron, E. 1986. The pronominal "copula" as agreement clitic. In H. Borer (ed.), Syntax of pronominal clitics, 313332. New York: Academic Press.

Frege, G. 1891/1960. Translations from the philosophical writings of Gottlob Frege. P. Geach and M. Black. Blackwell: Oxford.

Haeberli, E. 2003. Categorial features as the source of EPP and abstract case phenomena. In E. Brandner and H. Zinsmeister (eds.), New perspectives on case theory, 89-126. Stanford: CSLI Publications.

Haider, H. 2015. Head directionality - in syntax and morphology. In A. Fábregas, J. Mateu and M. Putnam (eds.), Contemporary linguistic parameters, 73-97. London: Bloomsbury Academic.

Haider, H. 2016. The chapter of incredible neglects. In Incredible syntax - between cognitive science and imposture, 1-44, Chapter I. Unpublished manuscript.

Hentschel, G. 2001. On the perspectivisation of noun phrases in copula sentences, mainly in Polish: (Y) to (jest) X and similar phenomena. In V. S. Chrakovskij, M. Grochowski, and G. Hentschel (eds.), Studies on the syntax and semantics of Slavonic languages, 161-213. Oldenburg: Bibliotheks- und Informationssystem der Universität Oldenburg.

Heycock, C. 2013. The syntax of predication. In M. Den Dikken (ed.), The Cambridge handbook of generative syntax, 322-352. Cambridge: Cambridge University Press.

Hiraiwa, K. 2002. Multiple Agree. 25th GLOW Workshop: Tools in Linguistic Theory, Utrecht: Institute of Linguistics.

Hiraiwa, K. 2005. Dimensions of symmetry in syntax: Agreement and clausal architecture. Ph.D. diss, Cambridge, The MIT Press.

Holmberg, A. 2000. Scandinavian stylistic fronting: How any category can become an expletive. Linguistic Inquiry 31: $445-483$.

Holmberg, A. 2010. Null subject parameters. In T. Biberauer, A. Holmberg, I. Roberts and M. Sheehan (eds.), Parametric variation: Null subjects in minimalist theory, 88-124. Cambridge: Cambridge University Press.

Kim, J. 1969. Events and their descriptions: Some considerations. In N. Rescher (ed.), Essays in honor of Carl G. Hempel, 198-215. Dordrecht: Reidel.

Kim, J. 1976. Events as property exemplifications. In M. Brand and D. Walton (eds.), Action Theory. Proceedings of the Winnipeg Conference on Human Action, 159-177. Dordrecht: Reidel.

Kiss, É. 2002. The EPP in a topic-prominent language. In P. Svenonius (ed.), Subjects, expletives and the EPP, 107124. New York: Oxford University Press.

Lasnik, H. 2001. A note on the EPP. Linguistic Inquiry 32: 356-362.

Maienborn, C. 2005. On the limits of the Davidsonian approach: The case of copula sentences. Theoretical Linguistics 31: 275-316.

Maienborn, C. 2007. On Davidsonian and Kimian states. In I. Comorovski and K. von Heusinger (eds.), Existence: Semantics and Syntax, 107-130. Dordrecht: Springer.

Maienborn, C. 2011. Event semantics. In K. von Heusinger, C. Maienborn and P. Portner (eds.), Semantics: An international handbook of natural language meaning, vol. 1, chap. 34: 802-829. Berlin: De Gruyter. 
Maienborn, C. 2019. Events and states. In R. Truswell (ed.), The Oxford handbook of event structure, 50-89. Oxford: Oxford University Press.

McCloskey, J. 1996. Subjects and subject positions in Irish. In R. D. Borsley and I. Roberts (eds.), The syntax of the Celtic languages: A comparative perspective, 241-283. Cambridge: Cambridge University Press.

Meillet, A. 1906. La phrase nominaleen indo-européen. Mémoires de la Société Linguistique de Paris 14: 1-26.

Mikkelsen, L. 2005. Copular clauses. Specification, predication and equation. Amsterdam and Philadelphia: John Benjamins.

Moro, A. 1997. The raising of predicates. Predicative noun phrases and the theory of clause structure. Cambridge: Cambridge University Press.

Parsons, T. 1990. Events in the semantics of English: A study in subatomic semantics. Cambridge: The MIT Press.

Partee, B. 1987. Noun Phrase interpretation and type shifting principles. In J. Groenendijk and M. Stokhof (eds.), Studies in discourse representation theory and the theory of generalized quantifiers. GRASS 8. Dordrecht: Foris.

Partee, B. 2000. Copula inversion puzzles in English and Russian. In K. Kusumoto and E. Villalta (eds.), Issues in semantics, 183-208. Amherst: University of Massachusetts.

Partee, B. 2010. Specificational copular sentences in Russian and English. In A. Grønn and I. Marijanovic (eds.), Russian in contrast. Grammar, 25-49. Oslo: University of Oslo.

Pesetsky, D., And Torrego, E. 2004. Tense, case and the nature of syntactic categories. In J. Guéron and J. Lecarme (eds.), The syntax of time, 295-537. Cambridge: The MIT Press.

Rizzi, L. 1982. Issues in Italian syntax. Dordrecht: Foris.

Rizzi, L. 1990. Relativised minimality. Cambridge: The MIT Press.

Roberts, I. 2010. A deletion analysis of null subjects. In T. Biberauer, A. Holmberg, I. Roberts and M. Sheehan (eds.), Parametric variation: Null subjects in minimalist theory, 58-87. Cambridge: Cambridge University Press.

Roberts, I., and A. Roussou. 2002. The extended projection principle as a condition on the tense dependency. In P. Svenonius (ed.), Subjects, expletives and the EPP, 125-155. New York: Oxford University Press.

Rothstein, S. 1983. The syntactic forms of predication. Ph.D. diss, MIT, Cambridge.

Rothstein, S. 1995. Pleonastics and the interpretation of pronouns. Linguistic Inquiry 26: 499-529.

Rothstein, S. 2004. Predicates and their subjects. Dordrecht: Springer Science \& Business Media.

Rutkowski, P. 2006. From demonstratives to copulas: A cross-linguistic perspective and the case of Polish. Journal of Universal Language 7: 147-175.

Sigurðsson, H. A. 2003. Case: abstract vs. morphological. In E. Brandner and H. Zinsmeister (eds.), New perspectives on case theory, 223-268. CSLI Publications.

Svenonius, P. 2002. Introduction. In P. Svenonius (ed.), Subjects, expletives and the EPP, 3-28. New York: Oxford University Press.

Tajsner, P. 2015a. On focus marking and predication. Evidence from Polish with some notes on Hausa. Lingua Posnaniensis 57(1): 113-138.

Tajsner, P. 2015b. On specification predication and the derivation of copular to-clauses in Polish. Studia Anglica Posnaniensia 50(4): 25-66.

Ura, H. 2000. Checking theory and grammatical functions in universal grammar. Oxford: Oxford University Press. Vangsnes, Ø. 2002. Icelandic expletive constructions and the distribution of subject types. In P. Svenonius (ed.), Subjects, expletives and the EPP, 43-70. New York: Oxford University Press.

Williams, E. 1980. Predication. Linguistic Inquiry 11(1): 203-238.

Woodard, A. 2018. Predication and identity in copular sentences. Ph.D. diss, Durham, Durham University.

Zamparelli, R. 2000. Layers in the determiner phrase. New York: Garland.

Zeiljstra, H. 2012. There is only one way to agree. The Linguistic Review 29: 491-539. 